\title{
Trends in Clinical Prediction Models of Stroke Outcomes Research: A Bibliometric Analysis
}

\author{
Mustapha Mohammed ${ }^{1,2}$, Hadzliana Zainal ${ }^{1 *}$, Siew Chin Ong1, Fatimatuzzahra' Abd Aziz ${ }^{1}$, Abubakar Sha'aban ${ }^{1,2}$, Sagir \\ Mustapha ${ }^{3,4}$, Irene Looi $^{5}$ and Balamurugan Tangiisuran ${ }^{1,6}$

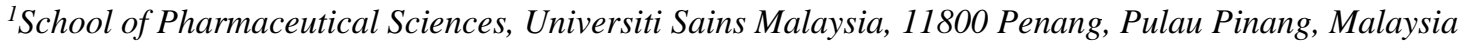 \\ ${ }^{2}$ Department of Clinical Pharmacy and Pharmacy Practice, Faculty of Pharmaceutical Sciences, Ahmadu Bello \\ University, Zaria, Kaduna, Nigeria \\ ${ }^{3}$ Department of Pharmacology, School of Medical Sciences, Universiti Sains Malaysia, 16150 Kubang Kerian,
} Kota Bharu, Kelantan, Malaysia

${ }^{4}$ Department of Pharmacology and Therapeutics, Ahmadu Bello University Zaria, Kaduna, Nigeria

${ }^{5}$ Clinical Research Centre, Hospital Seberang Jaya, Pulau Pinang, Malaysia

${ }^{6}$ National Poison Center, Universiti Sains Malaysia, 11800 Penang, Pulau Pinang, Malaysia

\begin{abstract}
Stroke is one of the leading causes of death and disability globally. Clinical models have been reported to predict stroke outcomes and could potentially guide clinical decisions. This study aimed to describe the global trends of research activities in clinical prediction models of stroke outcomes. Bibliographic data of publications on clinical prediction models of stroke outcomes were extracted from the Scopus database from 2010 to 2019. The studies were quantitatively analysed and visualised using VOSviewer software. A total of 6,364 (48.8\%) eligible original publications were included in the final analysis. The number of articles published (n) and citations received (c) had increased steadily since 2010. The most productive journals were "Stroke" ( $\mathrm{n}=679, \mathrm{c}=20,385)$, "Journal of Stroke and Cerebrovascular Diseases" $(\mathrm{n}=586, \mathrm{c}=4968)$ and PLOS One $(\mathrm{n}=210$, c=2897). The top most cited articles were authored by Lip et al. (2010), Berkhemer et al. (2015) and Sanna et al. (2014). The United States (US), China and the United Kingdom (UK) contributed most to publications in the field. Our study showed steady increasing research activities in prediction models of stroke outcomes since 2010, with saturation in recent years. The articles were published in high-quality stroke-related journals and by high-income countries, suggesting the need to reinforce research capacities through collaborative networks.
\end{abstract}

Keywords: bibliometric analysis; prediction models; Scopus; stroke; VOSviewer

\section{INTRODUCTION}

Stroke is one of the primary causes of death and disability worldwide (Feigin et. al., 2017; Katan \& Luft, 2018). Stroke outcomes vary significantly, and require a timely diagnosis to achieve optimal care. The outcomes after stroke could be complex, multidimensional and depend on several clinical variables (Ingeman et. al., 2017; Mohammed et al., 2020). Therefore, early prediction of stroke outcomes and understanding of the disease could lead to effective care. The clinical prediction of stroke outcomes has emerged as a tool that assists clinicians to predict outcomes for individual patients with stroke (Thourani et al., 2019).

The clinical prediction models utilise patient characteristics to determine the predictive power for estimating the chances of developing futuristic outcomes (Fahey et. al., 2018; EWOUT, 2019). These estimates are now utilised in patients risk classification (Meyer et al., 2015). The predictor variables for stroke outcomes include demographics (e.g., gender and age) and medical history 
(e.g., hypertension and surgery) (Mohammed et al., 2020). The stroke outcomes that could be predicted include survival and functional status (Brown et al., 2015). Several other prediction models of stroke outcomes have been discussed in the literature (Thourani et. al., 2019; Lee et. al., 2019; Baturova et. al., 2019; Pan et. al., 2018; Fahey et al., 2018).

In recent years, bibliometric analysis has become a widely accepted tool for evaluating the impact of publications, knowledge and research trends (Thompson \& Walker, 2015; Hicks et al., 2015). Previous bibliometric analyses were primarily conducted on stroke as a disease and were mostly limited to specific countries and regions (Alarcon-Ruiz et. al., 2019; Malhotra et. al., 2018; Salhab et. al., 2018; Chuang et al., 2007). No study currently describes the global research trends in clinical prediction models of stroke outcomes. Thus, this study aimed to analyse the trends in research output in clinical prediction models of stroke outcomes in recent years.

\section{METHODS}

\section{A. Search Strategy}

A search was conducted on Scopus (available at https://www.scopus.com/) to identify relevant publications related to prediction models of stroke outcomes in the past decade (2010-2019). The final search was done in April 2020. The search strategy includes a combination of the following terms: stroke outcomes/risks, clinical prediction models/scores, clinical prognostic models/scores, regression models. Only original articles were included. The search strategies and flowchart of included studies are presented as Supplementary Material 1 and Figure 1, respectively.

Scopus (Elsevier BV) is a major citation database of scientific literature, containing $>35,000$ titles from about 12,000 international publishers, with about 34,000 peerreviewed sources in top-ranked areas, including health sciences (Kulkarni et al., 2009). Scopus reports four types of journal quality indicators; CiteScore, SJR (SCImago Journal Rank), SNIP (Source Normalised Impact per Paper), and hindex (Hoogendoorn, 2008; Kähler, 2010; Aghaei Chadegani et. al., 2013; Martín-Martín et al., 2018). The Scopus database was used in this study because it includes more sources than all other common databases like Web of
Science (WoS) and Medline (PubMed). In addition, we have full access to the Scopus database.

\section{B. Statistical Analysis}

The searched publications were downloaded as commaseparated values (CSV) from the Scopus database. Microsoft Excel 2016 (Microsoft, DC, US) was used to import the data and quantitatively analysed. The summary of the results was presented in tables (frequencies, percentages), and figures and mapping networks.

The Scopus "analyse results" option was used to compute the number of annual publications, journals, authors, institutions, countries, and citations. The journals' metrics, such as Citations, CiteScore, SJR, and SNIP for 2018, were equally extracted from the database. The contributions of the publications were assessed depending on the number of articles and citations received.

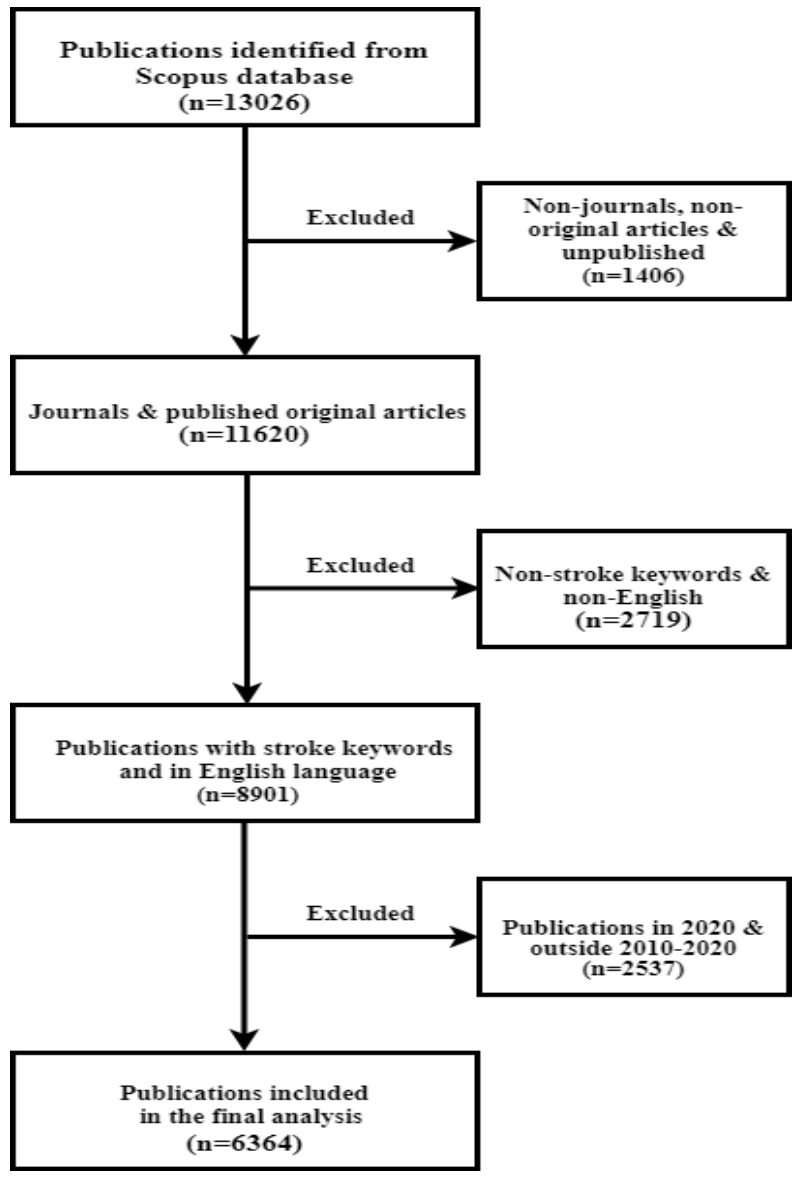

Figure 1. Flow chart of articles included in the bibliometric analysis 
Visualisation maps using VOSviewer, version 1.6.14 (Leiden, Netherlands) were conducted to demonstrate the links within a cluster of authors, countries, institutions, or keywords. Each node represented an author (country or institution), and the size of each node represents the activity measured in terms of publications output. The description of visualisation maps was based on the colours, size, and distance of the networks. The larger the distance between two items in the network, the less they are related.

\section{RESULTS}

\section{A. Annual Publications Output}

A total of 6364 eligible original articles on clinical prediction models of stroke outcomes published in recent years (2010 2019) were analysed. The publications increased steadily from 2010 until 2017, followed by a consecutive decline in 2018 and 2019 due to saturation. We identified 2012, 2013,
2014, and 2017 as the milestone years after categorising the output as years with $\geqslant 100$ publications and a growth rate of $\geqslant 10 \%$ compared to the previous year.

\section{B. Journals}

The most productive journal based on the number of articles published (n) and citations (c) is "Stroke" ( $\mathrm{n}=679$, c=20,385), followed by "Journal of Stroke and Cerebrovascular Diseases" ( $n=586, c=4968)$, "PLOS One" (n=210, c=2897), "Cerebrovascular Diseases" (n=175, c=3355), "International Journal of Stroke" (n=162, c=2393) and "Neurology" (n=140 articles, $c=4289)$. The top 10 productive journals contributed $36.1 \%$ of the total publications in the field. "Stroke" was the most contributive journal in the area (CiteScore 4.94, SJR 3.422, and SNIP of 1.886). The top 10 contributive journals are presented in Table 1.

Table 1. The top contributive journals on clinical prediction models of stroke outcomes

\begin{tabular}{ccccc}
\hline Rank & Journals & Publications & Citations & Citescores \\
\hline 1 & Stroke & 679 & 20385 & 4.94 \\
2 & Journal of Stroke and Cerebrovascular Diseases & 586 & 4968 & 1.78 \\
3 & PLOS One & 210 & 2897 & 2.97 \\
4 & Cerebrovascular Diseases & 175 & 3355 & 2.58 \\
5 & International Journal of Stroke & 162 & 2393 & 3.08 \\
6 & Neurology & 140 & 4289 & 3.85 \\
7 & BMC Neurology & 93 & 1026 & 2.44 \\
8 & European Journal of Neurology & 91 & 1351 & 3.37 \\
9 & Journal of The Neurological Sciences & 84 & 1213 & 1.97 \\
10 & Archives of Physical Medicine and Rehabilitation & 78 & 1296 & 3.03 \\
\hline
\end{tabular}

\section{Articles}

Table 2 shows the top 10 articles on clinical prediction models of stroke outcomes. The top most cited article was titled "Refining clinical risk stratification for predicting stroke..." authored by Lip et al. (2020), and published in the
Chest (c=3448), followed by "A randomised trial of intraarterial treatment..." (Berkhemer et. al., 2015; the New England Journal of Medicine, $\mathrm{c}=3013$ ) and "Cryptogenic stroke and underlying atrial fibrillation" (Sanna et. al., 2014, NEJM, $\mathrm{c}=881$ ). 
Table 2. The top most cited articles on clinical prediction models of stroke outcomes

\begin{tabular}{|c|c|c|}
\hline Rank & First Author/Year/Title/Journal & Citations \\
\hline 1 & $\begin{array}{l}\text { Lip Gregory, 2010. "Refining clinical risk stratification for predicting stroke and thromboembolism in } \\
\text { atrial fibrillation using a novel risk factor-based approach: The Euro Heart Survey on atrial } \\
\text { fibrillation". Chest. }\end{array}$ & 3448 \\
\hline 2 & $\begin{array}{l}\text { Berkhemer Olvert, 2015. "A randomised trial of intraarterial treatment for acute ischemic stroke". } \\
\text { New England Journal of Medicine. }\end{array}$ & 3013 \\
\hline 3 & $\begin{array}{l}\text { Sanna Tommaso, 2014. "Cryptogenic stroke and underlying atrial fibrillation". New England Journal } \\
\text { of Medicine. }\end{array}$ & 881 \\
\hline 4 & $\begin{array}{l}\text { Olesen Jonas, 2011. "Validation of risk stratification schemes for predicting stroke and } \\
\text { thromboembolism in patients with atrial fibrillation: nationwide cohort study". British Medical } \\
\text { Journal. }\end{array}$ & 837 \\
\hline 5 & $\begin{array}{l}\text { Saposnik Gustavo, 2011. "Diagnosis and management of cerebral venous thrombosis: A statement for } \\
\text { healthcare professionals from the American Heart Association/American Stroke Association". Stroke. }\end{array}$ & 807 \\
\hline 6 & $\begin{array}{l}\text { "Obstructive sleep apnea-hypopnea and incident stroke: The sleep heart health study". American } \\
\text { Journal of Respiratory and Critical Care Medicine. }\end{array}$ & 708 \\
\hline 7 & $\begin{array}{l}\text { Lip Gregory, 2011. "Comparative validation of a novel risk score for predicting bleeding risk in } \\
\text { anticoagulated patients with atrial fibrillation: The HAS-BLED score". Journal of the American } \\
\text { College of Cardiology. }\end{array}$ & 636 \\
\hline 8 & $\begin{array}{l}\text { Friberg Leif, 2012. "Evaluation of risk stratification schemes for ischaemic stroke and bleeding in } 182 \\
678 \text { patients with atrial fibrillation: The Swedish Atrial Fibrillation cohort study". European Heart } \\
\text { Journal. }\end{array}$ & 585 \\
\hline 9 & $\begin{array}{l}\text { Reilly Paul, 2014. "The effect of dabigatran plasma concentrations and patient characteristics on the } \\
\text { frequency of ischemic stroke and major bleeding in atrial fibrillation patients". Journal of the } \\
\text { American College of Cardiology. }\end{array}$ & 497 \\
\hline 10 & $\begin{array}{l}\text { Lansberg Maarten, 2012. "MRI profile and response to endovascular reperfusion after stroke } \\
\text { (DEFUSE 2): A prospective cohort study". Lancet Neurology. }\end{array}$ & 493 \\
\hline
\end{tabular}

\section{Authors}

The most contributive author was Lip Gregory $(n=78$, $c=8866$, h-index $=55)$, followed by Wang Yongjun $(n=56$, $\mathrm{c}=652)$, Wang Yilong $(\mathrm{n}=55, \mathrm{c}=705)$, Zhao Xingquan $(\mathrm{n}=55$,

$c=761)$, and Schwamm Lee $(n=51, c=1559)$. The top 10

contributive authors are shown in Table 3.

Table 3. The top productive authors on clinical prediction models of stroke outcomes

\begin{tabular}{ccccc}
\hline Rank & Author & Publications & Citations & h-index \\
\hline 1 & Lip Gregory & 78 & 8866 & 155 \\
2 & Wang Yongjun & 56 & 652 & 44 \\
3 & Wang Yilong & 55 & 705 & 33 \\
4 & Zhao Xingquan & 55 & 761 & 31 \\
5 & Schwamm Lee & 51 & 1559 & 84 \\
6 & Michel Patrik & 49 & 1079 & 44 \\
7 & Elkind Mitchell & 44 & 1684 & 69 \\
8 & Ovbiagele Bruce & 43 & 681 & 61 \\
9 & Smith Eric Edward & 41 & 1341 & 81 \\
10 & Lees Kennedy & 40 & 1348 & 82 \\
\hline
\end{tabular}




\section{E. Countries}

A total of 107 countries contributed to the field of clinical prediction models of stroke outcomes. The topmost productive countries were the United States, US ( $\mathrm{n}=188 \mathrm{o}$, $\mathrm{c}=46,592$ ), followed by China ( $\mathrm{n}=922, \mathrm{c}=9449$ ), United Kingdom, UK ( $\mathrm{n}=715, \mathrm{c}=24908)$, Germany ( $\mathrm{n}=517, \mathrm{c}=19010)$, and Canada $(\mathrm{n}=424, \mathrm{c}=13399)$. The top 10 productive countries contributed $96.8 \%$ of the total publications in the field. The number of publications from the US, China, and the UK combined constituted more than $50 \%$ of the top 10 productive countries. The details of the top 10 productive countries are shown in Table 4.

Table 4. The top productive countries on clinical prediction models of stroke outcomes

\begin{tabular}{cccc}
\hline Rank & Countries & Publications & Citations \\
\hline 1 & United States & 1880 & 46592 \\
2 & China & 922 & 9449 \\
3 & United Kingdom & 715 & 24908 \\
4 & Germany & 517 & 19010 \\
5 & Canada & 424 & 13399 \\
\hline
\end{tabular}

\begin{tabular}{rccc}
\hline 6 & South Korea & 384 & 4503 \\
7 & Australia & 360 & 8872 \\
8 & Japan & 345 & 5453 \\
9 & Italy & 321 & 12533 \\
10 & Taiwan & 294 & 4862 \\
\hline
\end{tabular}

\section{F. Collaborations}

The top collaborative authors were Lip G, Wang Y, and Zhang Y. The top collaborative institutions were the Department of Neurology and Epidemiology in Beijing, China, and the US. Also, the top collaborative countries were the US, China, and the UK. The results of co-authorship analysis for countries are presented in Figure 2.

The co-occurrence analysis showed the interaction between keywords relevant to clinical prediction models of stroke outcomes, majorly "stroke" as presented in Figure 3.

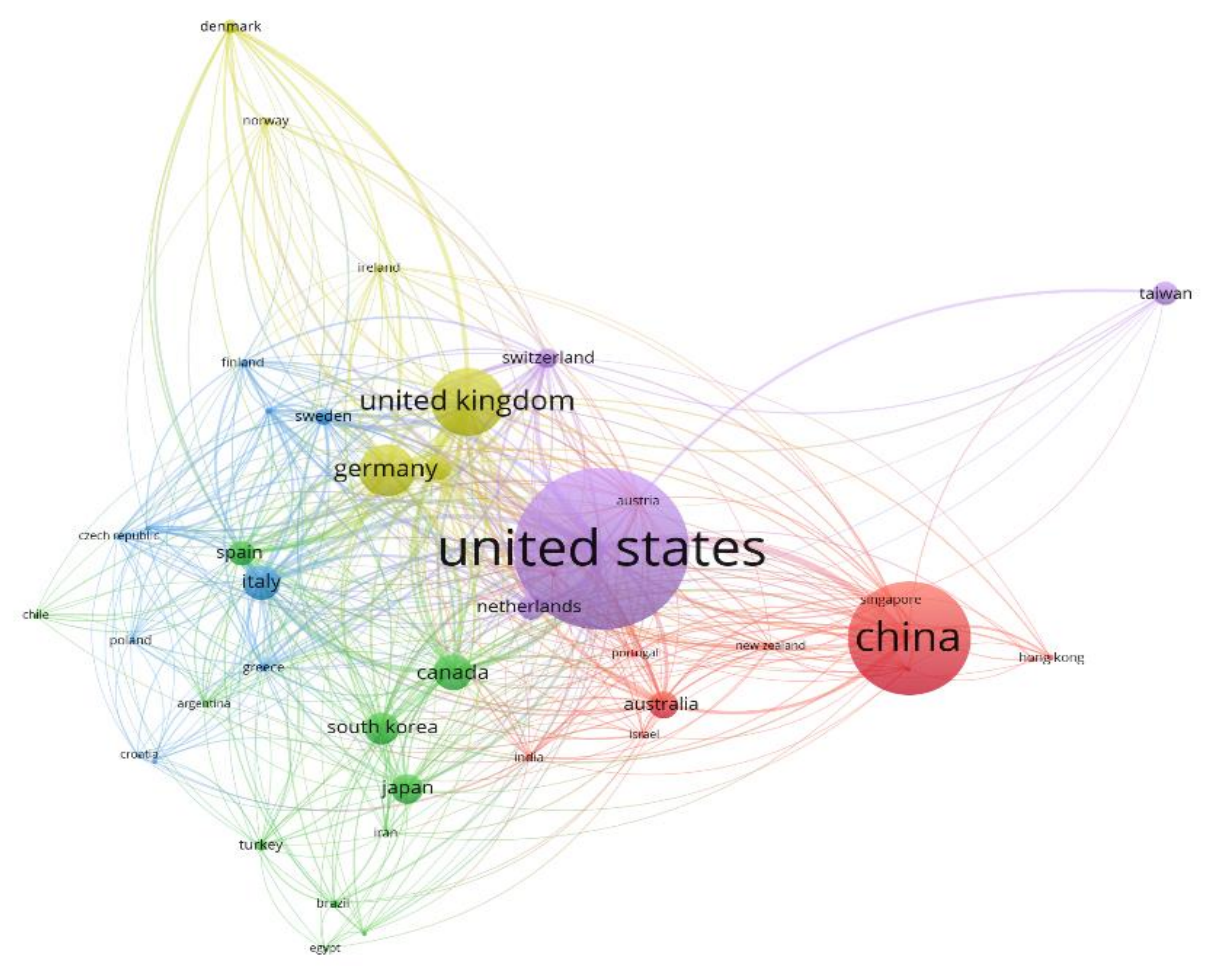

Figure 2. Co-authorship analysis of countries in clinical prediction models of stroke outcomes 


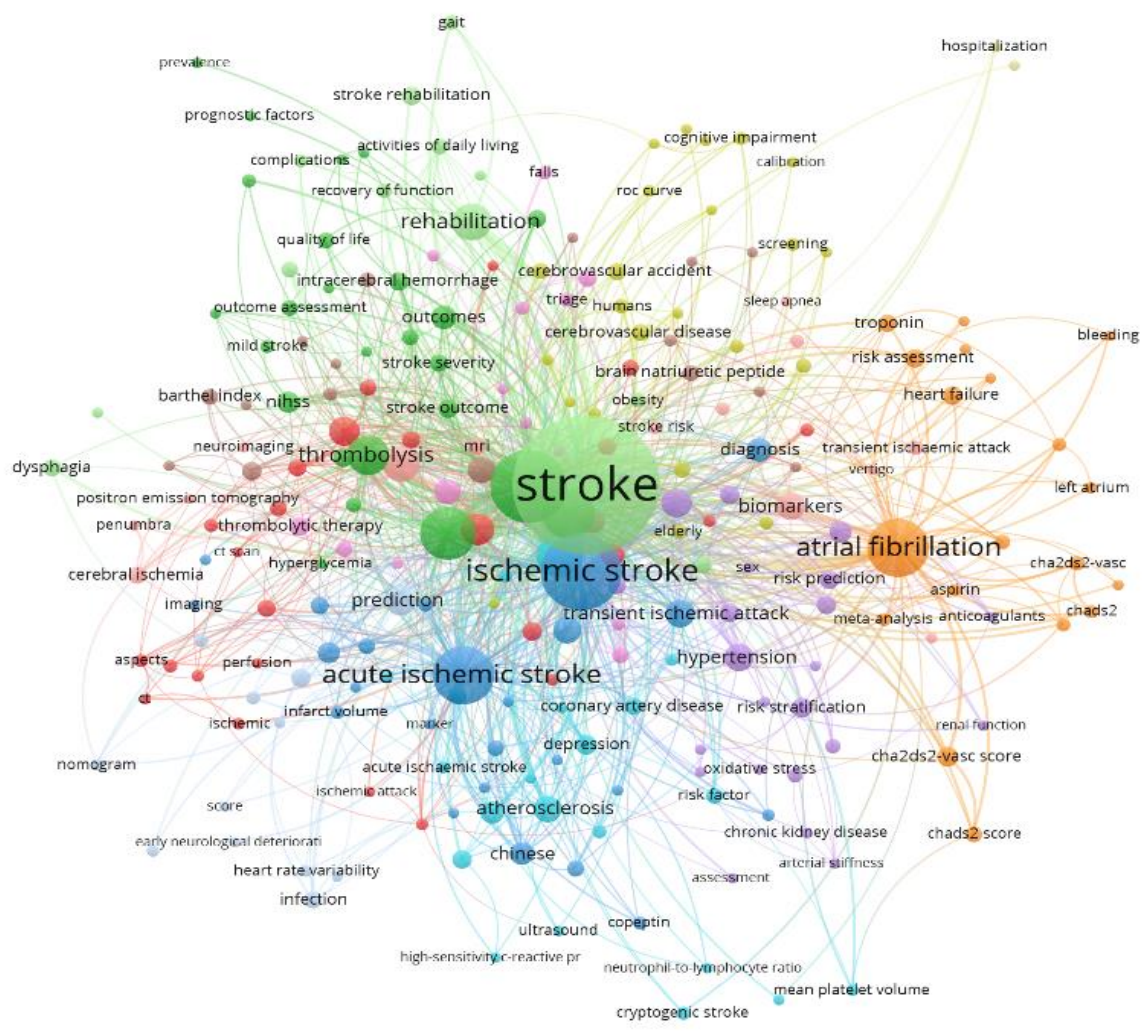

Figure 3. Co-occurrence analysis of keywords in clinical prediction models of stroke outcomes

\section{DISCUSSION}

Our study provided a global overview of the trends in scientific publications in clinical prediction models of stroke outcomes during the past decade (2010 - 2019). Several studies on prediction models of stroke outcomes have been reported (Fahey et. al., 2018; Thourani et. al., 2019; Baturova et. al., 2019; Smith et. al., 2015; Saposnik et al., 2013). These studies have highlighted promising models with potential clinical applications. Unlike reviews, which provide the reader with in-depth research advancements in a specific subject, bibliometric studies focus on research trends and networking in a particular subject area. Several bibliometric studies and citation analyses in clinical researches have been conducted using VOSviewer (Yang et. al., 2020; Ramos-Rincón et. al., 2019; Wang et. al., 2019; Stern et al., 2019), HistCite (Yang et. al., 2020, Shen et. al., 2019, Shen et al., 2018), and MTI (Stern et. al., 2019, Ramos-Rincón et al., 2019) applications. The citations generally reflect on the quality of the research and equate well with other indicators of research accomplishment (Ibrahim et. al., 2012, Parker et. al., 2013, Waltman, 2016).
The number of publications produced in a particular research field is a key indicator that measures the growth of such a field. Our study demonstrated that publications in the clinical prediction models of stroke outcomes had steadily increased since 2010, with saturation in 2018 and 2019. The earlier growth in the publications suggested an ongoing effort to provide evidence of stroke outcome clinical prediction models with potential clinical applications. Evaluation of overall growth in a particular research field has been reported (Price, 1986). According to the report, the research growth of a specific field passes through four stages: (1) the precursor stage, where a few researchers begin to publish in the new area, (2) the exponential growth phase, which involves expansion in the number of researchers and size of the field, (3) the consolidation stage, the field gain recognition as a body of knowledge, and (4) the peak phase, where there is a decline in productivity in the field (Price, 1986, Dabi et al., 2016). This final phase reflects maturity and saturation in the field, resulting in a significant reduction of publications (Dabi et al., 2016). The latter 
reflects the last two years of saturation experienced in our study.

The distribution of research activities in our study indicates that the top journals were the primary sources of publications in clinical prediction models of stroke outcomes. Our results showed that higher quartile journals (Q1 or Q2) had higher quality of publications, resulting in citations, and increased Citescores, suggesting high impact. Each citation reflects the evaluation of researchers on exciting and relevant articles to their work (Bergstrom, 2007). CiteScore is the latest metric launched in late 2016 by Elsevier as a substitute to the commonly used Journal Citation Report (JCR) impact factor (IF) (Van Noorden, 2016). A journal's CiteScore calculates the average number of citations to recent papers published in that journal yearly (RoldanValadez et al., 2019). This metric has since evolved into a modern standard that provides a more complete, clear, and up-to-date picture of a journal's impact. Other metrics include SJR and SNIP. All the top productive journals in our study have some things in common: they are neurovascularbased journals and are recommended for keeping up with the latest developments in stroke outcome research. Notably, "Stroke", a reputable journal of cerebral circulation, placed first among the most productive journals, indicating its remarkable impact in our study field.

The prediction of stroke and outcomes articles published by Lip 2010 (the Chest), Berkhemer 2015 (NEJM), Sanna 2014 (NEJM) were the leading productive publications and citations. In addition, Lip, Wang Yongjun, and Wang Yilong were the topmost productive authors. This means that the articles presented exciting findings relevant to other similar studies that cited them. One of the most accurate indicators of scientific quality is the number of citations a publication obtains (Eyre-Walker \& Stoletzki, 2013). The aim of authorship, according to most researchers, is to produce high-quality papers with high citations. However, only about $14 \%$ of all publications turn out to be impactful, as most articles are not cited, except by their authors (Weinstein, 2007). The publication stage is an essential part of the research process because it impacts the author, organisation and journal rankings (Gasparyan, 2010).

The US, China, and the UK are the major countries contributing to clinical prediction models of stroke outcomes. So also, the respective institutions, including Massachusetts General Hospital US, Harvard Medical School US, and Capital Medical University China. The publication from these countries and institutions could be ascribed to their advancement in science and technology and the availability of research funding and national strategic supports (Luengo-Fernandez et. al., 2015; Zhu et. al., 2015; Landis et al., 2012). The US was the top productive country, suggesting its higher academic reputation. The top-ranked institutions are in the US, Europe, and China, further illustrating that these countries play dominant roles in the field. These advanced countries have been working actively towards developing more efficient stroke prevention and management strategies (Kim et. al., 2017; Malhotra et. al., 2018; Mohammed et al., 2018). Also, all the top contributing countries have advanced economies, and no low-income country was included among the top in the field. These findings are consistent because the prevalence of stroke is currently higher in developed countries, while the less developed and underdeveloped countries suffer from majorly infectious diseases and malnutrition (Collaborators, 2018; Mohammed et al., 2020). The burden of particular diseases determines the national funding priorities for health and academic researchers. China, for example, is a developing country. Large cities have added more to the population of stroke patients and are shouldering greater responsibility for stroke treatment (Wang et al., 2017).

Throughout the scientific disciplines in academia, two essential indicators are used as proxies for the quality of researchers: publishing peer-reviewed journal papers and winning research funding. Research funding bodies have generally believed that introducing funds into the research will encourage more research, generating impactful findings (Yang et al., 2013). Despite the importance of funding in research, it is not by itself sufficient to fast-track progress into real-world applications. Therefore, funding would preferably be structured to align with these needs. Our study identified the most productive funding sponsors as the NIH US, NNSFC China, and NINDS US.

The present study has the following limitations. First, the data were obtained solely from Scopus. Retrieving data from other databases such as WoS and PubMed could have provided extensive resources that may require more 
sophisticated analysis. However, Scopus is the most prominent and reliable source for bibliometric studies. Some research from countries like China, Germany, South Korea may publish in their local language in their region. Thus, an intrinsic language bias can underrate some contributions to clinical prediction models of stroke outcome. We relied on secondary data; any inconsistency arising from the initial indexing may be extended to our findings.

\section{CONCLUSION}

Our study provides a comprehensive overview of global research trends in clinical prediction models of stroke outcomes during the past decades. The study showed a steady increase in research activities in the clinical prediction of stroke outcomes since 2010, with saturation in recent years. The bulk of the publications are published in high-quality stroke-related journals and high-income countries, majorly in the US. Clinicians and researchers could track progress and reinforce research capacity in the field by developing multi-regional collaborative networks.

\section{FUNDING}

This work did not receive any form of funding.

\section{CONFLICT OF INTEREST}

The authors declare that they have no competing interests.

\section{REFERENCES}

Aghaei Chadegani, A, Salehi, H, Yunus, M, Farhadi, H Fooladi, M, Farhadi, M \& Ale Ebrahim, N 2013, 'A comparison between two main academic literature collections', Web of Science and Scopus databases, Asian Social Science, vol. 9, no. 18-26.

Alarcon-Ruiz, CA, Diaz-Barrera, ME, Vera-Monge, VA, AlvaDiaz, C \& Metcalf, T 2019, 'A Bibliometric Analysis of the Latin American Research on Stroke 2003-2017', World Neurosurg, vol. 129, pp. e545-e554.

Baturova, MA, Lindgren, A, Shubik, YV, Carlson, J \& Platonov, PG 2019, 'Interatrial block in prediction of allcause mortality after first-ever ischemic stroke', BMC Cardiovasc Disord, vol. 19, p. 37.

Bergstrom, C 2007, 'Eigenfactor: Measuring the value and prestige of scholarly journals', College \& Research Libraries News, vol. 68, pp. 314-316.

Brown, AW, Therneau, TM, Schultz, BA, Niewczyk, PM \& Granger, CV 2015, 'Measure of functional independence dominates discharge outcome prediction after inpatient rehabilitation for stroke', Stroke, vol. 46, pp. 1038-44.

Chuang, K-Y, Huang, Y-L \& Ho, Y-S 2007, 'A bibliometric and citation analysis of stroke-related research in Taiwan', Scientometrics, vol. 72, pp. 201-212.

Collaborators, GLROS 2018, 'Global, regional, and countryspecific lifetime risks of stroke, 1990 and 2016', New England Journal of Medicine, vol. 379, pp. 2429-2437.
Dabi, Y, Darrigues, L, Katsahian, S, Azoulay, D, De Antonio, M \& Lazzati, A 2016, 'Publication Trends in Bariatric Surgery: a Bibliometric Study', Obes Surg, vol. 26, pp. 2691-2699.

Ewout, WS 2019, Clinical Prediction Models: A Practical Approach to Development, Validation, and Updating, Springer Nature.

Eyre-Walker, A \& Stoletzki, N 2013, 'The assessment of science: the relative merits of post-publication review, the impact factor, and the number of citations', PLoS Biol, vol. 11, pp. e1001675.

Fahey, M, Crayton, E, Wolfe, C \& Douiri, A 2018, 'Clinical prediction models for mortality and functional outcome following ischemic stroke: a systematic review and metaanalysis', PloS One, vol. 13, pp. e0185402.

Feigin, VL, Abajobir, AA, Abate, KH, Abd-Allah, F, Abdulle, AM, Abera, SF, Abyu, GY, Ahmed, MB, Aichour, AN, Aichour, I \& Aichour, MTE 2017, 'Global, regional, and national burden of neurological disorders during 19902015: a systematic analysis for the Global Burden of Disease Study 2015', The Lancet Neurology, vol. 16, pp. 877-897.

Flaherty, ML, Kissela, B \& Khatri, P 2019, Mortality of stroke patients treated with thrombolysis.

Gasparyan, AY 2010, 'Editorial from Editorial Board Member [Thoughts on Impact Factors and Editing of 
Medical Journals]', Inflammation \& Allergy-Drug Targets (Formerly Current Drug Targets-Inflammation \& Allergy), vol. 9, pp. 2-5.

Hicks, D, Wouters, P, Waltman, L, De Rijcke, S \& Rafols, I 2015, 'Bibliometrics: The Leiden Manifesto for research metrics', Nature, vol. 520, pp. 429-31.

Hoogendoorn, G 2008, 'Scopus: The continuing development of an abstract and citation database', The Serials Librarian, vol. 55, pp. 227-234.

Ibrahim, GM, Carter Snead Iii, O, Rutka, JT \& Lozano, AM 2012, 'The most cited works in epilepsy: Trends in the "Citation Classics"', Epilepsia, vol. 53, pp. 765-770.

Ingeman, A, Andersen, G, Thomsen, RW, Hundborg, HH, Rasmussen, HH \& Johnsen, SP 2017, 'Lifestyle Factors and Early Clinical Outcome in Patients with Acute Stroke: A Population-Based Study', Stroke, vol. 48, pp. 611-617.

Kähler, O 2010, 'Combining peer review and metrics to assess journals for inclusion in Scopus', Learned Publishing, vol. 23, pp. 336-346.

Katan, M \& Luft, A 2018, 'Global Burden of Stroke', Semin Neurol, vol. 38, pp. 208-211.

Kim, Y, Yoon, DY, Kim, JE, Park, KM, Lee, JH, Song, HK \& Bae, JS 2017, 'Citation Classics in Stroke: The Top-100 Cited Articles on Hemorrhagic Stroke', Eur Neurol, vol. 78, pp. 210-216.

Kulkarni, AV, Aziz, B, Shams, I \& Busse, JW 2009, 'Comparisons of citations in Web of Science, Scopus, and Google Scholar for articles published in general medical journals', JAMA, vol. 302, pp. 1092-1096.

Landis, SC, Amara, SG, Asadullah, K, Austin, CP, Blumenstein, R, Bradley, EW, Crystal, RG, Darnell, RB, Ferrante, RJ, Fillit, H \& Finkelstein, R 2012, 'A call for transparent reporting to optimise the predictive value of preclinical research', Nature, vol. 490, pp. 187-191.

Lee, SH, Kim, BJ, Han, MK, Park, TH, Lee, KB, Lee, BC, Yu, KH, Oh, MS, Cha, JK, Kim, DH \& Nah, HW 2019, 'Futile reperfusion and predicted therapeutic benefits after successful endovascular treatment according to initial stroke severity', BMC Neurol, vol. 19, p. 11.

Luengo-Fernandez, R, Leal, J \& Gray, A 2015, 'UK research spend in 2008 and 2012: comparing stroke, cancer, coronary heart disease and dementia', BMJ Open, vol. 5, pp. eoo6648.

Malhotra, K, Saeed, O, Goyal, N, Katsanos, AH \& Tsivgoulis, G 2018, 'Top-10o Highest-Cited Original Articles in Ischemic Stroke: A Bibliometric Analysis', World Neurosurg, vol. 111, pp. e649-e66o.
Martín-Martín, A, Orduna-Malea, E, Thelwall, M \& LópezCózar, ED 2018, 'Google Scholar, Web of Science, and Scopus: A systematic comparison of citations in 252 subject categories', Journal of Informetrics, vol. 12, pp. 1160-1177.

Menken, M, Munsat, TL \& Toole, JF 2000, 'The global burden of disease study: implications for neurology', Arch Neurol, vol. 57, pp. 418-20.

Meyer, MJ, Pereira, S, Mcclure, A, Teasell, R, Thind, A, Koval, J, Richardson, M \& Speechley, M 2015, 'A systematic review of studies reporting multivariable models to predict functional outcomes after post-stroke inpatient rehabilitation', Disabil Rehabil, vol. 37, pp. 131623.

Mohammed, M, Zainal, H, Tangiisuran, B, Harun, SN, Ghadzi, SM, Looi, I, Sidek, NN, Yee, KL \& Aziz, ZA 2020, 'Impact of adherence to key performance indicators on mortality among patients managed for ischemic stroke', Pharmacy Practice (Granada), vol. 18.

Mohammed, MF, Marais, O, Qureshi, AI, Bhulani, N, Ferguson, D, Abu-Alola, H, Nicolaou, S \& Khosa, F 2018, 'The Top 100 Most-Cited Articles in Stroke Imaging: A Bibliometric Analysis', Curr Probl Diagn Radiol, vol. 47, pp. 161-167.

Pan, Y, Peng, Y, Chen, W, Wang, Y, Lin, Y, He, Y, Wang, N \& Wang, Y 2018, 'THRIVE-c score predicts clinical outcomes in Chinese patients after thrombolysis', Brain Behav, vol. 8, pp. e00927.

Parker, JN, Allesina, S \& Lortie, CJ 2013, 'Characterising sa scientific elite (B): publication and citation patterns of the most highly cited scientists in environmental science and ecology', Scientometrics, vol. 94, pp. 469-480.

Price, DJ 1986, Little science, big science... and beyond, Columbia University Press New York.

Ramos-Rincón, JM, Pinargote-Celorio, H, BelinchónRomero, I \& González-Alcaide, G 2019, 'A snapshot of pneumonia research activity and collaboration patterns (2001-2015): a global bibliometric analysis. BMC medical research methodology', vol. 19, p. 184.

Roldan-Valadez, E, Salazar-Ruiz, SY, Ibarra-Contreras, R \& Rios, C 2019, 'Current concepts on bibliometrics: a brief review about impact factor, Eigenfactor score, CiteScore, SCImago Journal Rank, Source-Normalised Impact per Paper, H-index, and alternative metrics', Ir J Med Sci, vol. 188, pp. 939-951. 
Salhab, HA, Salameh, P, Hajj, H \& Hosseini, H 2018, 'Stroke in the Arab World: A bibliometric analysis of research activity (2002-2016)', eNeurologicalSci, vol. 13, pp. 40-45.

Saposnik, G, Cote, R, Mamdani, M, Raptis, S, Thorpe, KE, Fang, J, Redelmeier, DA \& Goldstein, LB 2013, 'JURaSSiC: accuracy of clinician vs risk score prediction of ischemic stroke outcomes', Neurology, vol. 81, pp. 448-55.

Shen, L, Wang, S, Dai, W \& Zhang, Z 2019, 'Detecting the Interdisciplinary Nature and Topic Hotspots of Robotics in Surgery: Social Network Analysis and Bibliometric Study', J Med Internet Res, vol. 21, pp. e12625.

Shen, L, Xiong, B, Li, W, Lan, F, Evans, R \& Zhang, W 2018, 'Visualising Collaboration Characteristics and Topic Burst on International Mobile Health Research: Bibliometric Analysis', JMIR Mhealth Uhealth, vol. 6, pp. e135.

Smith, CJ, Bray, BD, Hoffman, A, Meisel, A, Heuschmann, PU, Wolfe, CD, Tyrrell, PJ \& Rudd, AG 2015, 'Intercollegiate Stroke Working Party, G (2015) Can a novel clinical risk score improve pneumonia prediction in acute stroke care? A UK multicenter cohort study', J Am Heart Assoc, vol. 4, pp. eoo1307.

Stern, AD, Gordon, WJ, Landman, AB \& Kramer, DB 2019, 'Cybersecurity features of digital medical devices: an analysis of FDA product summaries', BMJ Open, vol. 9, pp. e025374.

Thompson, DF \& Walker, CK 2015, 'A descriptive and historical review of bibliometrics with applications to medical sciences', Pharmacotherapy, vol. 35, pp. 551-9.

Thourani, VH, O'brien, SM, Kelly, JJ, Cohen, DJ, Peterson, ED, Mack, MJ, Shahian, DM, Grover, FL, Carroll, JD, Brennan, JM \& Forcillo, J 2019, 'Development and Application of a Risk Prediction Model for In-Hospital Stroke After Transcatheter Aortic Valve Replacement: A Report from The Society of Thoracic Surgeons/American College of Cardiology Transcatheter Valve Therapy Registry', Ann Thorac Surg, vol. 107, pp. 1097-1103.

Van Noorden, R 2016, 'Controversial impact factor gets a heavyweight rival', Nature, vol. 540, pp. 325-326.

Waltman, L 2016, 'A review of the literature on citation impact indicators', Journal of Informetrics, vol. 10, pp. 365-391.

Wang, K, Xing, D, Dong, S \& Lin, J 2019, 'The global state of research in nonsurgical treatment of knee osteoarthritis: a bibliometric and visualised study', BMC Musculoskelet Disord, vol. 20, p. 407.

Wang, W, Jiang, B, Sun, H, Ru, X, Sun, D, Wang, L, Jiang, Y, Li, Y, Wang, Y \& Chen, Z 2017, 'Prevalence, Incidence, and
Mortality of Stroke in China: Results from a Nationwide Population-Based Survey of 480687 Adults', Circulation, vol. 135, pp. 759-771.

Weinstein, JN 2007, 'Threats to scientific advancement in clinical practice', Spine (Phila Pa 1976), vol. 32, pp. S5862.

Yang, C, Wang, X, Tang, X, Bao, X \& Wang, R 2020, 'Research trends of stem cells in ischemic stroke from 1999 to 2018: A bibliometric analysis', Clin Neurol Neurosurg, vol. 192, pp. 105740.

Yang, J, Vannier, MW, Wang, F, Deng, Y, Ou, F, Bennett, J, Liu, Y \& Wang, G 2013, 'A bibliometric analysis of academic publication and NIH funding', Journal of Informetrics, vol. 7, pp. 318-324.

Zhu, L, He, D, Han, L \& Cao, H 2015, 'Stroke Research in China over the Past Decade: Analysis of NSFC Funding', Transl Stroke Res, vol. 6, pp. 253-256. 